\title{
Ibuprofen-Amino Acids Co-Crystal Screening Via Co-Grinding Methods
}

\author{
Muhamad Fitri Othman ${ }^{1}$, Norasikin Jamburi ${ }^{1}$, Nornizar Anuar ${ }^{1}$, Syarifah Abd. Rahim ${ }^{2}$ and Nurul Hazwani Rohalim ${ }^{1}$ \\ ${ }^{1}$ Faculty of Chemical Engineering, UniversitiTeknologi MARA Malaysia (UiTM), 40450 Shah Alam, Selangor, MALAYSIA \\ ${ }^{2}$ Faculty of Chemical and Natural Resources Engineering, Universiti Malaysia Pahang (UMP), LebuhrayaTunRazak, 26300 \\ Gambang, Pahang, MALAYSIA
}

\begin{abstract}
The importance of pharmaceutical co-crystals now has been recognized in order to improve the research and development in pharmaceutical industries. Low solubility of active pharmaceutical ingredient (API) has led to the growth of new pharmaceutical co-crystals formation as it enhances the physicochemical properties of the API. In this works, preparation of new co-crystal formation between ibuprofen (IBP) with selected amino acid compounds were performed by using dry grinding and liquid assisted grinding (LAG) techniques. Ibuprofen (IBP) was selected as the API meanwhile glycine (GLY), L-alanine (ALA) and L-proline (PRO) were selected as co-crystal former (CCF) agents. The products of IBP-co-former from grinding experiments for the formation of co-crystals were characterized and verified using X-Ray Powder Diffraction (XRPD), Differential Scanning Calorimetry (DSC) and Fourier Transform Infra-Red Spectroscopy (FTIR). The finding reveals that the IBP-PRO co-crystals have successfully formed. For IBP-PRO system, new crystalline peaks from XRPD were recorded at $2 \theta$ values of $4.374^{\circ}, 5.436^{\circ}$ and $10.944^{\circ}$ from dry grinding technique and $4.41^{\circ}, 5.436^{\circ}$ and $10.962^{\circ}$ for liquid assisted grinding (LAG) technique. A new melting point of $257.49^{\circ} \mathrm{C}$ was discovered for IBP-ALA indicates the possibility of co-crystals formation. On the other hand, the analysis for IBP-GLY shows that no co-crystals formed in the system.
\end{abstract}

\section{Introduction}

Since decades ago and until now there is no exact definition of co-crystal. Although many researchers came by different definition, co-crystal is commonly accepted as a crystal built out of two or more organic components and basically in their pure solid forms, under ambient conditions. The importance of pharmaceutical co-crystal now has been recognized in order to improve the research and development in pharmaceutical industries [1]. For a poorly soluble active pharmaceutical ingredient (API), the co-crystal approaches will improve the API's solubility [2].

Not limited to solubility, co-crystal also helps in improving other physicochemical properties such as stability, dissolution, and bioavailability of poorly water soluble drugs [3]. The properties of drug co-crystal can be modified by forming pharmaceutical co-crystals that usually has two compounds which are single API and a relevant co-crystal former (CCF). Pharmaceutical cocrystal is a new level of pharmaceutical products as it offers a better option in optimizing the API physicochemical properties without changing the chemical composition of the API [4]. Any changes of properties due to the change of molecular composition of either the API or the CCF will affect the function of the drug.

Grinding method was used as a screening process for the possibility of pharmaceutical co-crystal formation. In this paper, the mechanochemical method with grinding in absence of solvent is termed as "dry grinding". Meanwhile the grinding experiment in the presence of solvent is termed as "liquid assisted grinding" (LAG). Grinding method is the most efficient method for cocrystallization screening process compared to solution crystallization method (the most common method) that relies on evaporation and cooling of stoichiometric solution. This is due to the fact that only a little amount of solvent needs to be used so that the co-crystal formation can occur by reaction in a small liquid phase and/or through amorphous phase formation [5], [6]. Ibuprofen was used as an API while amino acid as CCF is believed to improve the solubility of the API by cocrystallization process due to its zwitterionic state. However, it depends on the side chain of the amino acids which can be acidic or basic and strongly modifies the behaviour of the molecules [7].

One of important rule of thumb before preliminary work for co-crystal screening is carried out is to investigate the possibility of proton transfer involves during hydrogen bonding interaction, which might lead to salt formation instead of co-crystal. The investigation of this possibility can be predetermined by measuring the acid ionization constant, $p K_{a}$. A common guideline is the 'rule of three' which states that a salt formation can be expected when the difference of $p K_{a}$ between the acid and the conjugate acid of the base is greater than 3 units [8]. Empirical solution chemistry demonstrates that a $p K_{a}$ 
difference of at least two units (between an acid and a base moiety) is required to form a salt that is stable in water [9]. Meanwhile, the $p K_{a}$ difference less than 3 units could result in co-crystal formation as the possibility of proton transfer is little. This rule is only a guideline that can be followed before preliminary work is conducted; however this rule is insufficient in verifying co-crystal formation. It is suggested that a crystal engineering approach must be based on complementary intermolecular interaction rather than just a single $p K_{a}$ value [10].

\section{Material and methods}

\subsection{Materials}

Ibuprofen (IBP) (MW: $206.29 \mathrm{~g} / \mathrm{mol}$ ) was obtained from Shasun Pharmaceutical Limited, India (Batch No.: IB 11070248)(SN Grade). The CCFs used were glycine, Lalanine and L-proline. Glycine (GLY) (MW: $75.07 \mathrm{~g} / \mathrm{mol}$ ) was purchased from Sigma-Aldrich with purity of $\geq 98 \%$ while L-alanine (ALA) (MW: $89.09 \mathrm{~g} / \mathrm{mol}$ ) and L-proline (PRO) (MW: $115.13 \mathrm{~g} / \mathrm{mol}$ ) were purchased from Merck KGaA, Darmstadt, Germany with purity of of $\geq 98 \%$. Fig. 1 shows the molecular structure of API and CCFs used in this research that obtained from Cambridge Structure Database (CSD).

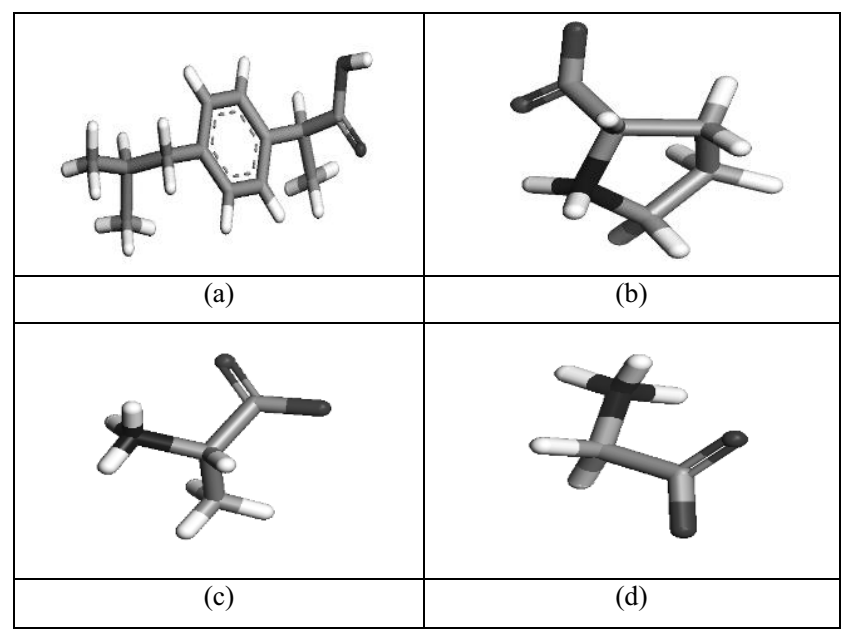

Figure 1. Molecular structure of (a) ibuprofen; (b) L-proline; (c) L-alanine and (d) Glycine obtained from Cambridge Structure Database (CSD).

\subsection{Milling methodology}

In this work, two milling methods were used; i.e. (dry grinding method and LAG method). Ibuprofen (IBP) was co-milled with one of the selected CCF in oscillatory ball mill (Mixer Mill MM400, Retsch GmbH, Germany) using a $25 \mathrm{~mL}$ milling vial. Four stainless steel beads with size of $6 \mathrm{~mm}$ in diameter were used in the milling process. The IBP and the CCF were co-milled in stoichiometric ratio of $1: 1(0.01 \mathrm{~mol}, 2.0658 \mathrm{~g}: 0.01 \mathrm{~mol}$, $1.1541 \mathrm{~g}), 1: 2(0.01 \mathrm{~mol}, 2.0675 \mathrm{~g}: 0.02 \mathrm{~mol}, 2.3378 \mathrm{~g})$ and 2:1 (0.02mol, 4.1233g:0.01mol, 1.1553g). The milling process was operated for 30 minutes at frequency of 30
Hz. For LAG method, 2 drops of solvent (ethanol) were added into the mixture of IBP and the CCF before the milling process starts.

\section{Characterization methods}

\subsection{X-Ray Powder Diffraction (XRPD)}

The co-crystal formation was determined using an XRPD, Rigaku D/Max-2000 (Rigaku, Japan) with $\mathrm{Cu} \mathrm{K \alpha}$ radiation at a wavelength of $1.542 \AA$ in continuous scanning mode. The scanning rate used was $0.1285^{\circ}$ over $2 \theta / \mathrm{min}$ with the step size of $0.018^{\circ}$. The accelerating voltage of the XRPD used was $40 \mathrm{kV}$ and the current was $30 \mathrm{~mA}$. The data were collected over $2 \theta$ range of $5^{\circ}$ to $30^{\circ}$.

\subsection{Differential Scanning Calorimetry (DSC)}

Thermal analyses of the products were performed by using DSC (Mettler Toledo DSC 820) equipped with refrigeration cooling system. The products were weighed approximately to $6 \mathrm{mg}$ which then crimped in a nonhermetic aluminium pans $(30 \mu \mathrm{l})$ and scanned at a heating rate of $10{ }^{\circ} \mathrm{C} / \mathrm{min}$ in the range of $25{ }^{\circ} \mathrm{C}$ to $350{ }^{\circ} \mathrm{C}$. This process was run under continuously purged dry nitrogen environment at a flow rate of $50 \mathrm{~mL} / \mathrm{min}$.

\subsection{Fourier Transform Infra-Red Spectroscopy (FTIR)}

A Thermo Nicolet 6700 FTIR Spectrometer was used to collect the IR spectra of the sample. The information was then used for the analysis of the possibility of proton transfers between the molecules. The scan was collected over the range of 515 to $4000 \mathrm{~cm}^{-1}$ for each product. The data was analysed using OMNIC software.

\section{Results and discussion}

\subsection{Ionization constant rule for co-crystals formations}

The data was analysed using OMNIC software. The IBP and the amino acids used in this work have more than one $p K_{a}$ values, reflecting the ionization constants of acidic and basic moieties of the molecules. Table 1 shows the $p K_{a}$ values of both API and CCFs (i.e. ALA, GLY and PRO) used. Based on the 'rules of three', the result of $\Delta p K_{a}$ values shown in Table 1 indicates that there are possibilities of co-crystals formed instead of salt for IBPPRO, IBP-GLY and IBP-ALA systems. This is due to the fact that the difference between the $p K_{a}$ value of the individual component (i.e. between acidic and basic moiety) is more than 2 units, whilst the difference in the $p K_{a}$ values between the two mixture components is less than 3 units. However the $\Delta p K_{a 2}$ of IBP-GLY shows the difference of more than 3 units, which might indicate the possibility of non co-crystal to form. 
Table 1. The ionization constants for IBP the API and CCFs (ALA, PRO and GLY)

\begin{tabular}{|c|c|c|c|c|}
\hline Material & $p K_{a 1}{ }^{*}$ & $\begin{array}{c}p K_{a} \\
{ }^{*}\end{array}$ & $\begin{array}{c}\Delta p K_{a 1} \\
\text { (IBP- CCF) }\end{array}$ & $\begin{array}{c}\Delta p K_{a 2} \\
\text { (IBP-CCF) }\end{array}$ \\
\hline $\begin{array}{c}\text { Ibuprofen } \\
\text { (IBP) }\end{array}$ & 4.45 & $\begin{array}{c}12.6 \\
2\end{array}$ & - & - \\
\hline $\begin{array}{c}\text { L-alanine } \\
\text { (ALA) }\end{array}$ & 2.35 & 9.69 & 2.10 & 2.93 \\
\hline $\begin{array}{c}\text { L-proline } \\
\text { (PRO) }\end{array}$ & 1.99 & $\begin{array}{c}10.9 \\
6\end{array}$ & 2.46 & 1.66 \\
\hline $\begin{array}{c}\text { Glycine } \\
\text { (GLY) }\end{array}$ & 2.34 & 9.6 & 2.11 & 3.02 \\
\hline
\end{tabular}

"The values of $p K_{a}^{*}$ values were obtained from Dawson, 1959 [11]

\subsection{Thermal analysis for preliminary characterization of co-crystal}

The screening of the IBP-CCF formation was carried out using two co-grinding methods (dry grinding and LAG). The feed to the co-grinding experiment was 1:1 ratio of IBP to CCF. The ground products from the experiment were analyzed using DSC. Table 2 shows the summary of the result obtained from the experiments.

The result in Table 2 shows the summary of results concluded from the presence of new endotherm peaks detected in the DSC thermogram for the ground samples obtained from both IBP-ALA and IBP-PRO systems. However, for both samples, the presences of pure components were also detected, showing that the samples contain both possible co-crystals compounds and pure components of the starting materials. The dry grinding method was applied to all IBP-CCF mixture system, while the LAG method was only carried out for the IBPPRO system. The tabulated result shows that the combination of IBP-PRO and IBP-ALA has high possibility of forming co-crystals due to the presence of new endotherm peaks that might corresponds to a new crystalline phase. Meanwhile, the endotherm profile of IBP-GLY shows the presence of two peaks which correspond to pure IBP and GLY components, and with no new peak detected, which could indicate that cocrystal formation did not take place.

Table 2. The ticked signs show the presence of melting peaks of components in the DSC thermogram, representing co-crystals and pure components.

\begin{tabular}{|c|c|c|c|}
\hline $\begin{array}{c}\text { IBP-CC } \\
\text { System }\end{array}$ & Methods & $\begin{array}{c}\text { Cocrystals } \\
\text { formation }\end{array}$ & $\begin{array}{c}\text { Pure } \\
\text { Component }\end{array}$ \\
\hline IBP-GLY & Dry Grinding & $X$ & $\sqrt{ }$ \\
\hline IBP-ALA & Dry Grinding & $\sqrt{ }$ & $\sqrt{ }$ \\
\hline IBP-PRO & Dry Grinding & $\sqrt{ }$ & $\sqrt{ }$ \\
\hline IBP-PRO & $\begin{array}{c}\text { Liquid-Assisted } \\
\text { Grinding (LAG) }\end{array}$ & $\sqrt{ }$ \\
\hline
\end{tabular}

L-proline appears to be an excellent candidate as a $\mathrm{CCF}$ as it shares the zwitterionic $\alpha$-ammoniumcarboxylate synthon, which is common to all other natural amino acids favouring the main chain atom interaction [7]. Different with other amino acids, Lproline is a constrained, rather rigid compound. In terms of formation of co-crystals, this rigidity can certainly be viewed as an entropic advantage over other, more flexible, conformer (entropic contribution) [7]. Assessment of Lproline as a $\mathrm{CCF}$ was further investigated using different stoichiometric mol ratio, i.e. 1:2 (IBP:PRO) and 2:1 (IBP:PRO) as both methods show a favourable result for the formation of IBP co-crystal.

The characterization on the thermal behaviour of the samples was analysed by using DSC. Fig. 2(a-d) shows the thermograms patterns for the starting materials (pure API and CCFs) and the ground product of IBP-CCF using selected grinding method.

Thermal behaviour analysis was carried out using the Differential Scanning Calorimetry by heating the samples between $25^{\circ} \mathrm{C}$ to $400{ }^{\circ} \mathrm{C}$ at $10{ }^{\circ} \mathrm{C} / \mathrm{min}$ heating rate. The DSC results show the IBP melts at $76.9{ }^{\circ} \mathrm{C}$ and evaporates at $285.38{ }^{\circ} \mathrm{C}$. Meanwhile, GLY melts at 253.26 ${ }^{\circ} \mathrm{C}$, ALA melts at $286.49{ }^{\circ} \mathrm{C}$. From Fig. 2(a), the heat analysis shows that the ground product consists of a mixture of IBP and GLY, and no co-crystal formation detected, as only the pure components peaks were observed. Meanwhile from Fig. 2(b), the endothermic peak of the ground product of IBP-ALA were present at the pure component of IBP peak. However, a new pek was observed at $257.49{ }^{\circ} \mathrm{C}$, which could indicate a new phase. Nevertheless, the presence of two peaks from this results could indicate the presence of IBP and a new phase in the ground product IBP-ALA.

The endothermic peaks of L-Proline shows some variable peaks which indicates the eutectic point and the melting point of the co-former at $118.39{ }^{\circ} \mathrm{C}$ and $223.34{ }^{\circ} \mathrm{C}$, respectively [12]. Fig. 2(c) and 2(d) show the results for IBP-PRO systems for both dry grinding and LAG method, using different stoichiometric ratios between the IBP and PRO. For dry grinding method, only one peaks was observed, i.e. at $73.76^{\circ} \mathrm{C}$ (for all IBP:PRO ratios), which corresponds for IBP peak. Meanwhile, for LAG method, a new peak was observed at $107.89^{\circ} \mathrm{C}$ for 1:1 IBP:PRO ground product, which could indicate a new crystalline phase system. For 1:2 IBP:PRO system, one peak also was observed, at $104.16{ }^{\circ} \mathrm{C}$ and this could belong to the PRO peak or a new crystalline phase. However, for 2:1 IBP:PRO system, only IBP peak at $73.76{ }^{\circ} \mathrm{C}$ was observed.

The new phase detected from the thermal analysis could belong to the co-crystals, salt crystals or solvates. Thus, a FTIR analysis was carried out to ensure the type of crystals formed in the ground product.

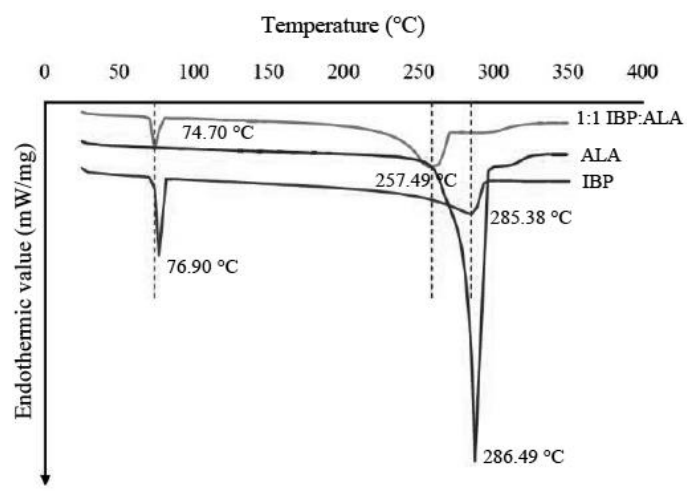

(a) 


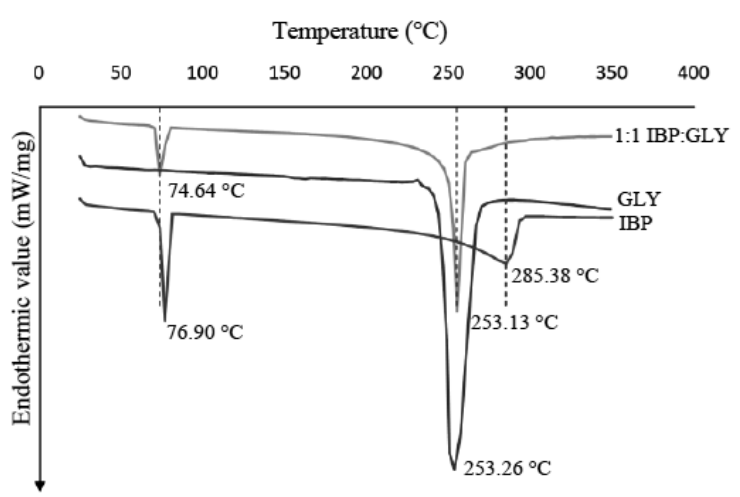

(b)

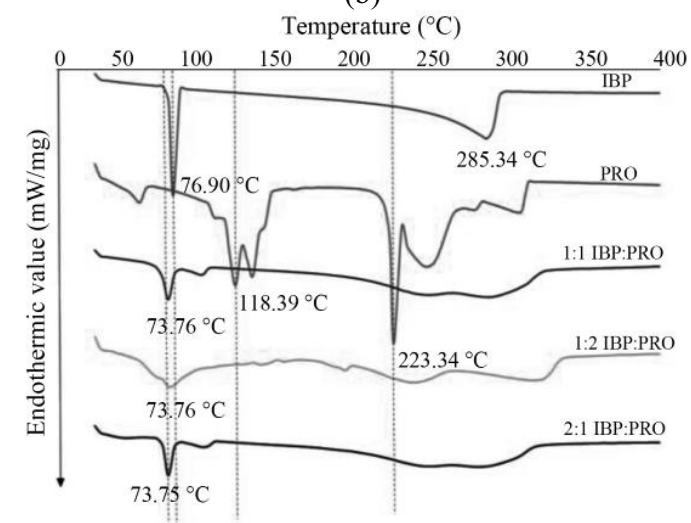

(c)

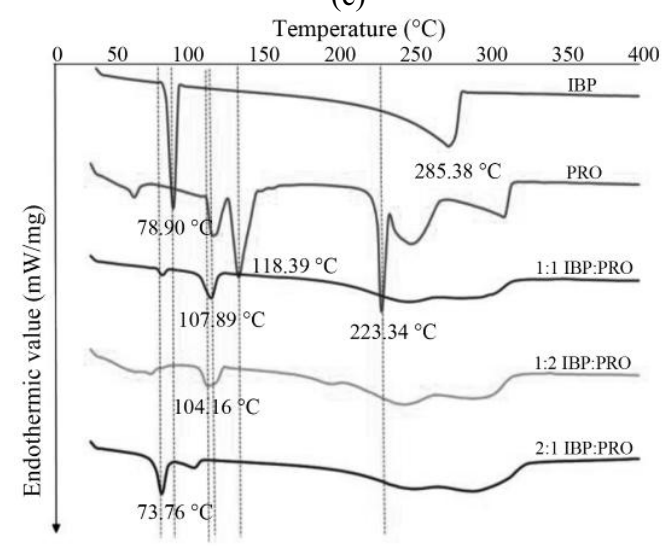

(d)

Figure 2. Thermograms of the sample obtain after grinding of IBP and CCF. (a) IBP and GLY (Dry grinding); (b) IBP and ALA (Dry grinding); (c) IBP and L-Proline (Dry grinding); and (d) IBP and L-Proline (Liquid Assisted Grinding)

\subsection{Proton transfer analysis for salt formation}

The FTIR spectra of the sample IBP-PRO in the range $>1500 \mathrm{~cm}^{-1}$ was analysed and the characteristic IR absorption band were compare with the pure IBP and pure PRO system. From Fig. 1 (a), the functional group of ibuprofen consists of aromatic ring and carboxylic acid whilst for L-proline contains an aliphatic ring, carboxyl group and amine group (Fig. 1(b)). The IR spectrum for 1:1 IBP:PRO (LAG) (Fig. 3) shows peaks at $1634.42 \mathrm{~cm}^{-}$ 1 for $\mathrm{C}=\mathrm{C}$ stretching, $1711.30 \mathrm{~cm}^{-1}$ for $-\mathrm{C}=\mathrm{O}$ in carboxylic acid, $1981.36 \mathrm{~cm}^{-1}$ for $\mathrm{C}-\mathrm{H}$ vibration in $\mathrm{R}$ $\mathrm{CH}=\mathrm{CH}_{2}, 2553.95 \mathrm{~cm}^{-1}$ for $-\mathrm{OH}$ in carboxylic acid, $2868.40 \mathrm{~cm}^{-1}$ and $2953.81 \mathrm{~cm}^{-1}$ for $-\mathrm{CH}_{3}$. This results show that there are no proton transfer activity for this $1: 1$ IBP:PRO from LAG method.

There are possibilities of proton transfer at both pure component (IBP and PRO) as both consist of $-\mathrm{COOH}$ bond and $\mathrm{PRO}$ has more advantage of proton transfer as it has the $-\mathrm{NH}^{+}$and $-\mathrm{COO}^{-}$functional group. The $-\mathrm{COO}^{-}$of the PRO has the possibility for proton transfer activity by accepting one $\mathrm{H}^{+}$to become $-\mathrm{COOH}$ and the $-\mathrm{NH}^{+}$of PRO will have the possibility for removing one proton to become $-\mathrm{NH}$. Thus from the result, it can be concluded that no solvates were observed, but however, the formation of salt (or proton transfer) for PRO cannot be concluded.

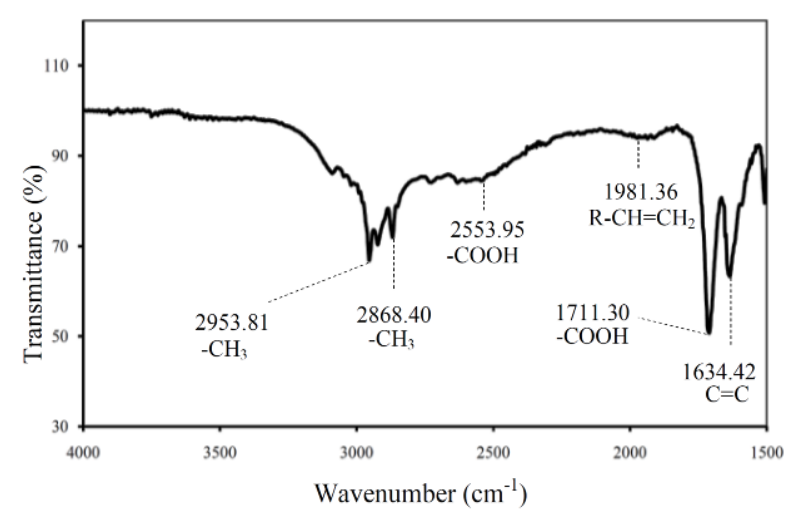

Figure 3. IR Spectra for 1:1 IBP-PRO (LAG method)

\subsection{Crystalline structure phase change determination}

Fig. 4 (a) and (b) shows the comparison of XRPD patterns of the feed materials of IBP, L-proline and the ground products of IBP-PRO systems recovered from both grinding methods. For the product of IBP-PRO system, ratios between IBP and PRO were varies stoichiometrically, i.e. $1: 1,2: 1$ and $1: 2$ for IBP-PRO crystalline products from both grinding.

The XRPD data show that new peaks were detected in all IBP:PRO ratios for both grinding methods. Table 3 also shows that common peaks were recorded for the same stoichiometric ratio for method dry grinding and LAG methods. However, there are some new peaks recorded for LAG samples which were not observed in the product of the dry grinding. This is probably due to the presence of the ethanol solvent in the samples in which ethanol enhances the formation of co-crystal which results in increasing of intensity of new peaks. The same effects also were reported by Trask and co-workers [13] in their work in co-crystallization of caffeine and glutaric acid using dry grinding and LAG methods [14]. For dry grinding method, the XRPD pattern confirms the presence of the unique new crystalline peaks but the DSC results do not show new peak in its thermograms.

By looking at Fig. 4(a) and 4(b) for IBP:PRO ratios of $(2: 1)$ and $(1: 2)$; peaks for pure components were also detected. For instance, for IBP:PRO ratios of $(2: 1)$, IBP peaks present together with the new phase peaks. Whilst for $(1: 2)$ ratios, PRO peaks were also detected. This is related to the act of the compound as limiting reactant in 
the combination. As for IBP:PRO (2:1), the L-proline act as the limiting reactant due to no peak of L-proline discovered but there was peak of IBP discovered for the sample. The remaining of IBP that not consumed lead to the peak of IBP observed in XRPD for the sample IBP:PRO (2:1) ratios in Fig. 4(a) and 4(b). Meanwhile for IBP:PRO (1:2) system, the IBP acted as the limiting reactant as the same peak of PRO observed in the sample. This shows that the stoichiometric of 1:1 IBP:PRO system is the best option as both compound (IBP and PRO) were almost completely consumed as no same peak of both compound observed in the sample.

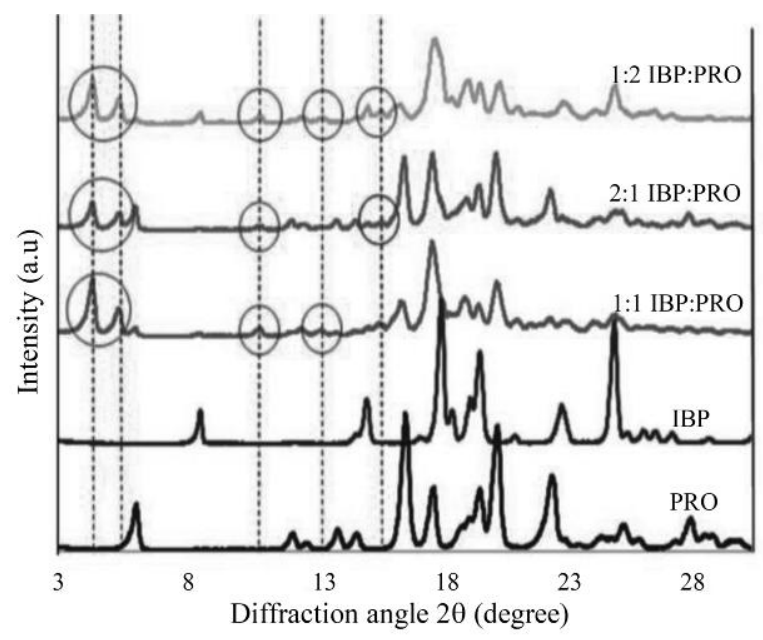

(a)

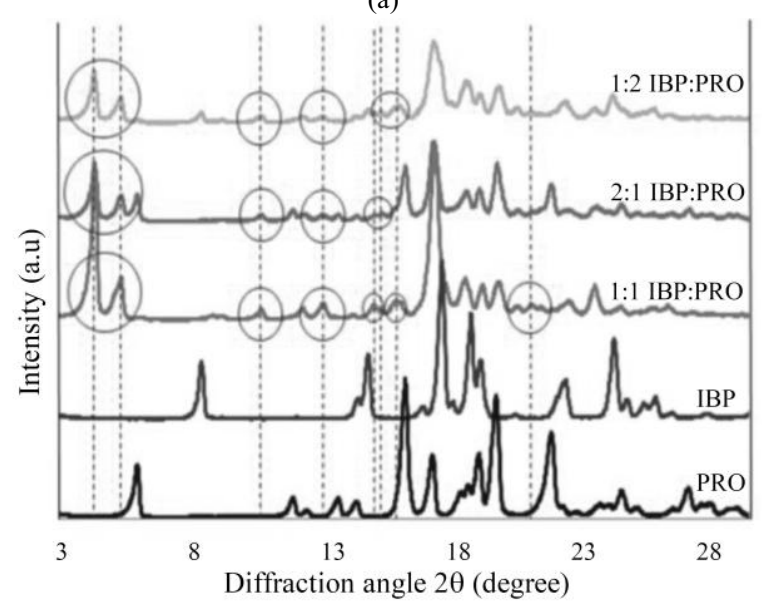

(b)

Figure 4. XRPD patterns of IBP, PRO and IBP-PRO ground products obtained from (a) dry grinding method; and (b) Liquid Assisted Grinding method. New peaks were observed and shown by dotted lines on the graph and the $2 \theta$ for the new peaks are listed in Table 3.

Table 3. Peaks observed from the XRPD analysis, showing possibility of the presence of a new crystalline form.

\begin{tabular}{|c|c|c|c|}
\hline $\begin{array}{c}\text { Co-crystal } \\
\text { Formation } \\
\text { Methods }\end{array}$ & $\begin{array}{c}\text { IBP- } \\
\text { PRO } \\
\text { ratio }\end{array}$ & New peak & $\begin{array}{c}\text { Peak from raw } \\
\text { materials }\end{array}$ \\
\hline $\begin{array}{c}\text { Dry } \\
\text { Grinding }\end{array}$ & $1: 1$ & $\begin{array}{c}4.338^{\circ}, 5.382^{\circ}, \\
10.854^{\circ}, 13.824^{\circ}\end{array}$ & $\begin{array}{c}\text { No peaks from } \\
\text { raw materials } \\
\text { observed }\end{array}$ \\
\hline
\end{tabular}

\begin{tabular}{|c|c|c|c|}
\hline & $2: 1$ & $\begin{array}{c}4.32^{\circ}, 5.364^{\circ} \\
10.818^{\circ}, 13.30^{\circ} \\
15.606^{\circ}\end{array}$ & $\begin{array}{c}\text { Peaks from } \\
\text { ibuprofen } \\
\text { observed }\end{array}$ \\
\hline & $1: 2$ & $\begin{array}{l}4.338^{\circ}, 5.382^{\circ} \\
10.872^{\circ}, 15.57^{\circ}\end{array}$ & $\begin{array}{c}\text { Peaks from L- } \\
\text { proline } \\
\text { observed }\end{array}$ \\
\hline \multirow{3}{*}{$\begin{array}{l}\text { Liquid } \\
\text { Assisted } \\
\text { Grinding } \\
\text { (LAG) }\end{array}$} & $1: 1$ & $\begin{array}{c}4.392^{\circ}, 5.436^{\circ}, \\
10.926^{\circ}, 13.338^{\circ}, \\
15.300^{\circ}, 16.182^{\circ}, \\
21.438^{\circ}\end{array}$ & $\begin{array}{c}\text { No peaks from } \\
\text { raw materials } \\
\text { observed }\end{array}$ \\
\hline & $2: 1$ & $\begin{array}{c}4.374^{\circ}, 5.400^{\circ}, \\
10.872^{\circ}, 13.266^{\circ}, \\
15.534^{\circ}, 16.272^{\circ}\end{array}$ & $\begin{array}{c}\text { Peaks from } \\
\text { ibuprofen } \\
\text { observed }\end{array}$ \\
\hline & $1: 2$ & $\begin{array}{c}4.374^{\circ}, 5.418^{\circ}, \\
10.908^{\circ}, 13.248^{\circ}, \\
15.354^{\circ}, 15.624^{\circ}\end{array}$ & $\begin{array}{c}\text { Peaks from L- } \\
\text { proline } \\
\text { observed }\end{array}$ \\
\hline
\end{tabular}

\section{Conclusions}

The investigation on the possibility of co-crystal formation between ibuprofen (IBP) and three co-crystal formers (CCF) which are L-alanine (ALA), Glycine (GLY) and L-Proline (PRO) were carried out using cogrinding method. There was no co-crystal formation observed on IBP-GLY system and a slight possibility of co-crystal formation for the IBP-ALA system. However, the IBP-PRO system shows high possibility of co-crystal formation and the best combination for IBP-PRO system is by using 1:1 stoichiometric ratio through liquid assisted grinding method in which ethanol was used as a solvent. The other stoichiometric ratio which are $1: 2$ and 2:1 (IBP-PRO) are not suitable where excess of pure compound were found in the system. The IBP-PRO cocrystal formed was found to obey the 'rule of three' rule in which the $p K_{a}$ difference is 2.56 units and the new phase was formed, which is suspected a co-crystal. However, salt formation cannot be confirmed.

\section{Acknowledgment}

The authors would like to express their gratitude to Universiti Teknologi MARA for funding of this work. This work is part of grants (600-RMI/RAGS 5/3 (211/2014))

\section{References}

1. A. V. Trask, Mol. Pharmaceutics, 4, 9, (2007)

2. S. L. Childs, J. T. Chyall, Dunlap, V. N. Smolenskaya, B. C. Stahly, G. P. Stahly, J. Am. Chem. Soc., 126, 8 (2014)

3. J. F. Remenar, S. L. Morrissette, M. L. Peterson, B., Moulton, J. M. MacPhee, H. R., Guzma'n, O. Almarsson, J. Am. Chem. Soc., 125, 2 (2003)

4. William Jones, W.D. Samuel Motherwell, A. V. Trask, MRS Bull., 31, 4 (2006)

5. R. Thakuria, A. Delori, W. Jones, M. P. Lipert, L. Roy, N. Rodriguez-Hornedo, Int. J. Pharm., 453, 25 (2013) 
6. D.R. Weyna, T. Shattock, P. Vshweshwar, M. J. Zaworotko, Cryst. Growth Des., 9, 18 (2009)

7. A. Tilborg, B. Norberg, J. Wouters, Eur. J. Med. Chem., 74, 16 (2014)

8. J. Wouters, L. Quere, RSC, (2012)

9. N. Blagden, M. d. Matas, P. Gavan, P. York, Adv. Drug Deliv. Rev., 59, 14 (2007)

10. S. L. Childs, G. Stahly, A. Park, Mol. Pharmaceutics, 4, 15 (2007)
11. R. M. Dawson, Oxford Clarendon Press, (1959)

12. A. Tillborg, C. Michaux, B. Norberg, J. Wouters, Eur. J. Med. Chem., 45, 7 (2010)

13. A. V. Trask, W.D. Samuel Motherwell, William Jones, Chem. Commun., 2 (2014)

14. N. Qiao, M. Li, W. Schlindwein, N. Malek, A. Davies, G. Trappitt, Int. J. Pharm., 419, 11 (2011) 